\title{
Cancer Health Disparities in Southeastern Wisconsin
}

\author{
Yi Ou* \\ Wisconsin Departmen tof Health Services, Madison, WI, USA
}

\section{Objective}

To assesse health disparities in all-site cancer incidence and mortality rates, and stage of specific cancer diagnosis (female breast cancer and colorectal cancer) compared between African American and white populations of southeastern Wisconsin during 2007-2011.

\section{Introduction}

Advanced cancer treatments and research have been helping reduce cancer mortality nationally and in Wisconsin. However, chronic health disparities in cancer remain a major public health concern as not all population subgroups have equal accesses to these healthcare benefits $[1,3]$. Previous cancer studies showed that cancer health disparities persisted among racial populations had primarily focused on the entire state of Wisconsin [2]. The southeastern region Wisconsin, the greater Milwaukee metropolitan area, is home to $83 \%$ of Wisconsin's African American population, and includes one of the most segregated metropolitan areas in the United States [1]. Because of this, better understanding of cancer trends in the southeastern Wisconsin region can assist in targeting a focal point to more effectively use resources to eliminate health disparities in Wisconsin.

\section{Methods}

Cancer incidence data were obtained from the Wisconsin Cancer Reporting System (WCRS) for the period 2007-2011. Cancer mortality data was assessed from the National Center for Health Statistics (NCHS) for the period 2007-2011. For absolute disparities, trends in cancer incidence, mortality, and the stage of diagnoses for African Americans and whites were calculated. Ratios of African American rates and white rates were used to measure changes in relative disparities [2].

\section{Results}

During 2000-2011, African Americans had higher cancer incidence rates and mortality rates than whites, except for breast cancer incidence rates were lower for African American women than for white women(Figures 1, 2, 3, and 4). Sex affected the trends in disparities and the magnitude of change for incidence rates(Table 1). In 2010, African American female breast cancer incidence rate was 8 cases per 100,000 population fewer than white rates. African American women tend to be diagnosed at a late stage of breast cancer with a rate ratio of 1.03 in 2000 and 1.29 in 2011. For colorectal cancer, African American men were more likely to be diagnosed with an advanced stage than white men with a slight decrease in disparity. The ratio between African American and white rates were 1.44 in 2000 and 1.40 in 2011

\section{Conclusions}

Reducing cancer burden and eliminiating cancer health disparities will need further research. But this study has shown that the at-risk population in the southeastern Wisconsin is a good starting point for public health profesisonals and policy markers to utilize their resources and priotize effectively to reduce racial health inequity in cancer in Wisconsin.

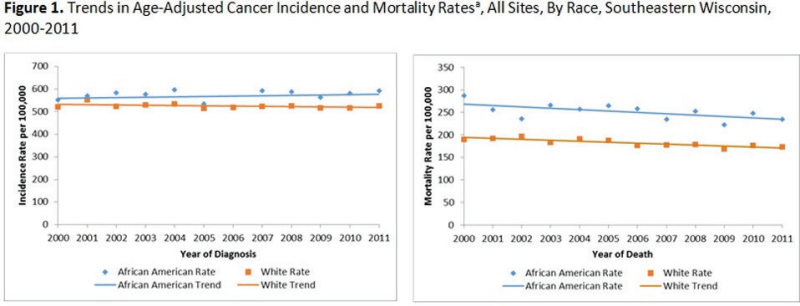

a Rates are per 100,000 persons and age-adjusted to the 2000 U.S. standard population.

Figure 2. Trends in Age-Adjusted cancer Incidence and Mortality Rates, All Sites, Females, by Race, Southeastern Wisconsin, 2000-2011

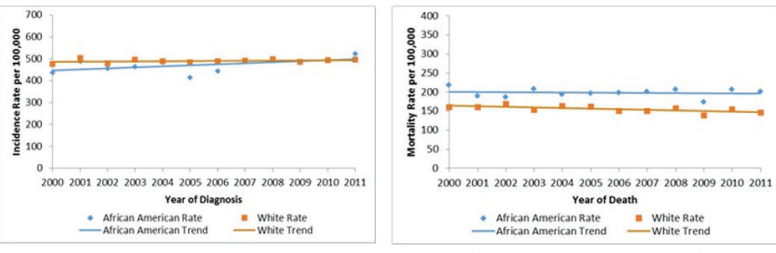

Figure 3. Trends in Age-Adjusted cancer Incidence and Mortality Rates, All Sites, Males, by Race, Southeastern Wisconsin, 2000-2011

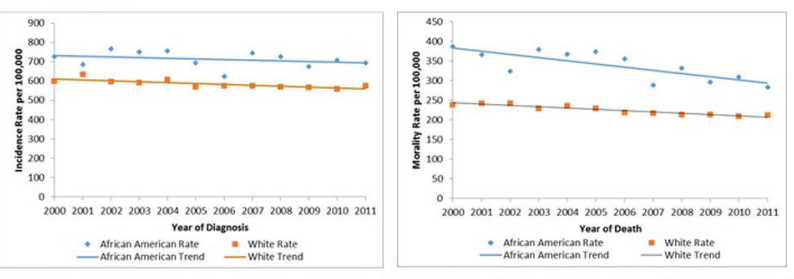

Figure 4. Trends in Age-Adjusted Female Breast Cancer Incidence and Mortality Rates, By Race, Southeastern Wisconsin, 2000-2011
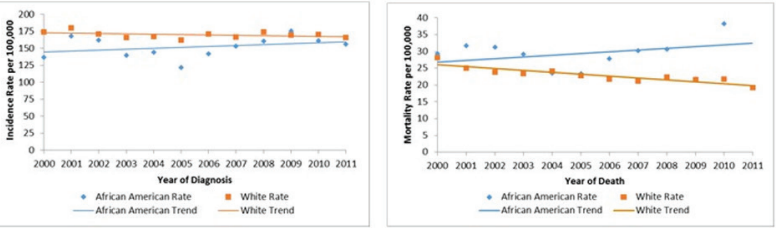

Table 1. Age-Adjusted Cancer Incidence and Mortality Rates ${ }^{2}$, All Sites, by Race and Sex, Southeastern

\begin{tabular}{|c|c|c|c|c|c|c|}
\hline & \multicolumn{3}{|c|}{2000} & \multicolumn{3}{|c|}{2011} \\
\hline & $\begin{array}{l}\text { African American } \\
\text { Rate }\end{array}$ & $\begin{array}{l}\text { White } \\
\text { Rate }\end{array}$ & $\begin{array}{l}\text { Rate } \\
\text { Ratiog }\end{array}$ & $\begin{array}{l}\text { African American } \\
\text { Rate }\end{array}$ & $\begin{array}{l}\text { White } \\
\text { Rate }\end{array}$ & $\begin{array}{l}\text { Rate } \\
\text { Ratio }\end{array}$ \\
\hline & \multicolumn{6}{|c|}{ Incidence } \\
\hline Both Sexes & 549.41 & 522.13 & 1.07 & 591.42 & 525.65 & 1.11 \\
\hline Male & 725.67 & 599.5 & 1.2 & 694.28 & 574.59 & 1.24 \\
\hline Female & 436.55 & 475.24 & 0.92 & 523.21 & 496.61 & 1.01 \\
\hline \multicolumn{7}{|c|}{ Mortality } \\
\hline Both Sexes & 286.89 & 189.79 & 1.39 & 234.18 & 172.93 & 1.35 \\
\hline Male & 386.58 & 237.72 & 1.58 & 282.64 & 212.07 & 1.14 \\
\hline Female & 217.46 & 160.51 & 1.22 & 201.01 & 146.35 & 1.33 \\
\hline
\end{tabular}

Keywords

cancer; Registry; Health equipty

\section{Acknowledgments}

Thank you for the sponsorship by CDC/CSTE Applied Public Health Informatics Fellowship to support the project at the Wisconsin Department of Health Services. I extend my gratitude to the Wisconsin Cancer Reporting System for giving me access to their data and advice for this project. 


\section{References}

1. American Cancer Society. Wisconsin Cancer Facts \& Figures 20132014. Atlanta, GA: American Cancer Society; 2013.

2. Jones N, Williamson A, Foote M, et al. Cancer health disparities persist among African Americans in Wisconsin. WMJ. 2010; 109 (5): 267273.

3. Underwood SM, Powe B, ey al. Cancer in US ethnic and racial minority populations. Ann Rev Nurs Res. 2004; 22: 217-263.Vilas P, Swain G, 4. Baumgardner D, et al. Health disparities in Milwaukee by socioeconomic status. WMJ. 2007; 106 (7): 366-372

*Yi Ou

E-mail: Yi.Ou@wisconsin.gov 